\title{
Formação docente decolonial em tempos de pandemia da COVID- 19: estratégias da tutoria presencial no curso de Pedagogia da Universidade Estadual de Goiás
}

\author{
Cleverson de Oliveira Domingos ${ }^{1}$ \\ Izabela Pereira e Lopes ${ }^{2}$
}

\section{RESUMO}

Esse artigo apresenta um relato de experiência sobre duas estratégias desenvolvidas pelas tutorias presenciais do Curso de Licenciatura em Pedagogia à distância, da Universidade Estadual de Goiás (UEG), para superar a suspensão dos encontros presenciais em $2020 \mathrm{em}$ razão da pandemia da COVID-19. No polo de Águas Lindas de Goiás (GO), foi desenvolvida a metodologia da Aprendizagem Baseada em Problemas (ABP) com o uso do WhatsApp, e no polo de Catalão-GO foram realizadas duas webconferência com especialista por meio do Google Meet. As atividades tiveram como objetivo introduzir reflexões decoloniais na formação de pedagogos. Por intermédio dessas experiências, os acadêmicos conheceram a perspectiva decolonial e refletiram sobre seus papéis na desconstrução de visões etnocêntricas sobre os povos negros e indígenas. Foi possível verificar que o trabalho colaborativo na tutoria é capaz de gerar resultados positivos e imprevistos, potencializando aprendizagens e formando uma verdadeira comunidade de aprendizagem em rede.

Palavras-chave: Pedagogia Decolonial. Aprendizagem Baseada em Problemas. WhatsApp. Webconferência. Google Meet.

\footnotetext{
${ }^{1}$ cleversondomingos@gmail.com - Secretaria de Estado de Educação do Distrito Federal

2 izabela.lopes@timedeautores.org.br - Universidade Estadual de Goiás
} 
Decolonial teaching training in COVID-19 pandemic times: presential tutoring strategies in the Pedagogy course of the State University of Goiás

\section{ABSTRACT}

This article presents an experience report on two strategies developed by the face-to-face tutoring of the Pedagogy Degree Course at a distance from the State University of Goiás to overcome the lack of face-to-face meetings in 2020 due to the COVID-19 pandemic. At the Águas Lindas de Goiás-GO pole, the Problem-Based Learning (PBL) methodology was developed using WhatsApp and at the Catalão-GO pole, two web conferences with specialists were held through Google Meet. The activities aimed to introduce decolonial reflections in the training of pedagogues. Through these experiences, academics got to know the decolonial perspective and reflected on their roles in deconstructing ethnocentric views about black and indigenous peoples. It was possible to verify that collaborative work in tutoring is capable of generating positive and unforeseen results, enhancing learning and forming a true networked learning community.

Keywords: Decolonial pedagogy. Problem-Basead Learning. WhatsApp. Web conferencing. Google Meet. 
A Universidade Estadual de Goiás (UEG), inserida no sistema Universidade Aberta do Brasil (UAB), oferta, desde 2017, o Curso de Licenciatura em Pedagogia na modalidade de Educação a Distância (EaD) por meio do Centro de Ensino e Aprendizagem em Rede (CEAR). O curso iniciou com turmas em dez polos de apoio presencial da UAB, localizados nos municípios de Águas Lindas de Goiás, Alexânia, Alto Paraíso, Catalão, Mineiros, Niquelândia, Posse, Santo Antônio do Descoberto, São Simão e Uruana. Essas turmas fazem parte da primeira experiência de oferta do curso de Pedagogia à distância pelo CEAR/UEG, e os estudantes se formaram no início de 2021. A partir de 2019, novas turmas passaram a ser ofertadas por meio de um novo convênio com a UAB e do programa UEG em Rede. Assim, atualmente, o curso está presente em 44 municípios do Estado de Goiás.

O curso de Pedagogia à distância da Universidade Estadual de Goiás está organizado em oito semestres, com carga horária total de 3.255 horas-aula. Em sua matriz curricular, há uma disciplina chamada História da Cultura Afro-brasileira e Indígena, com carga-horária teórica de 45 horas, que visa contribuir para a formação de docentes comprometidos com o combate ao racismo e a promoção dos direitos humanos e da igualdade étnico-racial. A disciplina foi ofertada no período do primeiro semestre de 2020 para acadêmicos do sétimo semestre do curso de Pedagogia dos polos de Águas Lindas de Goiás, Alexânia, Alto Paraíso, Catalão, Mineiros, Niquelândia, Posse, Santo Antônio do Descoberto, São Simão e Uruana. Este artigo irá abordar sobre as atividades desenvolvidas pelas tutorias presenciais no contexto de tal disciplina.

O primeiro semestre de 2020 iniciou com grandes expectativas no dia 20 de fevereiro de 2020. Nessa época, as informações sobre a disseminação de um novo coronavírus (SARS-CoV-2) entre humanos, identificado na cidade de Wuhan na China, já chegavam ao Brasil pelos noticiários. O Brasil confirmou o primeiro caso de COVID-19 no dia 26 de fevereiro de 2020. No dia 11 de março de 2020, a Organização Mundial da Saúde (OMS) declarou como pandemia a infecção humana pelo novo coronavírus, recomendando estratégias de isolamento e proteção para prevenir contaminações, salvar vidas e minimizar os seus impactos.

O cenário da pandemia impôs muitas adaptações nos sistemas de ensino brasileiro. Em todo o país, na Educação Básica e Superior, as atividades presenciais foram substituídas por alternativas de ensino mediadas pelo uso das tecnologias, com a adoção do Ensino Remoto Emergencial (HODGES et al., 2020). Em nível federal, uma das primeiras orientações veio do Ministério da Educação (MEC), por meio da Portaria $n^{\circ} 343$, de 17 de março de 2020, que permitiu a utilização de tecnologias e meios digitais para a realização das atividades que seriam presenciais por até 30 dias, prorrogáveis, a depender da orientação do Ministério da Saúde e dos órgãos de saúde estaduais, municipais e distritais (BRASIL, 2020a). Tal portaria foi depois ajustada e prorrogada pela Portaria ${ }^{\circ} 345$, de 19 de março de 2020 (BRASIL, 2020b) e pela Portaria $n^{\circ} 473$, de 12 de maio de 2020 (BRASIL, 2020d).

À medida que os casos de infecção pelo novo coronavírus aumentavam no Brasil, novas normativas eram publicadas e as antigas revogadas. Isso ocorreu nos diferentes níveis de governo e pelos diferentes órgãos. A Medida Provisória $n^{\circ}$ 934/2020, de $1^{\circ}$ de abril de 2020, editada pelo 
Governo Federal, dispensou as instituições de Educação Básica e Superior da obrigatoriedade de observância ao mínimo de dias de efetivo trabalho escolar e acadêmico (BRASIL, 2020c). Meses depois, o Ministério da Educação publicou a Portaria ${ }^{\circ} 544$, de 16 de junho de 2020, que autorizou a substituição das aulas presenciais por aulas em meios digitais até o final do ano de 2020 , revogando as portarias anteriores (BRASIL, 2020e).

O fato é que cada Estado e cada sistema de ensino precisou buscar alternativas para enfrentar a situação de pandemia do novo coronavírus. Em Goiás, o Poder Executivo do Estado decretou situação de emergência na Saúde Pública em virtude da pandemia por meio do Decreto estadual n 9.633, de 13 março de 2020 (GOIÁS, 2020a). Já o Conselho Estadual de Educação de Goiás (CEE-GO), por meio da Resolução nº2/2020, de 17 de março de 2020, estabeleceu o regime especial de aulas não presenciais com a manutenção das atividades pedagógicas sem a presença de alunos e professores nas dependências de ensino, como medida preventiva à disseminação da COVID-19 (GOIÁS, 2020b).

Na Universidade Estadual de Goiás, as atividades acadêmicas presenciais de todos os cursos foram suspensas a partir de 16 de março de 2020 por determinação da reitoria, que expediu a Portaria $n^{\circ}$ 560/2020-UEG (UEG, 2020a). Também foi instituído o regime de revezamento e teletrabalho para as atividades administrativas por meio da Portaria ${ }^{\circ} 563 / 2020$ UEG (UEG, 2020b). Nesse mesmo dia, em comunicado interno, a Coordenação Setorial do Curso de Pedagogia do CEAR/UEG suspendeu os encontros presenciais previstos para o mês de março e o atendimento dos tutores presenciais nos polos de EaD. A suspensão, que seria temporária, perdurou todo o ano de 2020 e se mantém neste ano de 2021, em razão do agravamento da pandemia da COVID-19.

Observando as normas editadas pelo Ministério da Educação, pelo Conselho Estadual de Educação de Goiás e pelos órgãos de saúde, a UEG elaborou a Instrução Normativa n 80/2020 que estabeleceu o Plano Emergencial de Ensino e Aprendizagem (PEEA) para os cursos de graduação da UEG, com o uso de tecnologias para mediação pedagógica (UEG, 2020c). Desta forma, o CEAR/UEG também teve que reestruturar suas atividades, uma vez que no Calendário Acadêmico e nos Planos de Cursos das graduações do CEAR estava prevista a realização de atividades presenciais mensais aos sábados nos polos de apoio presencial, que foi suspensa por conta da situação de pandemia.

Diante de todo esse cenário de novas diretrizes para as atividades pedagógicas, os tutores presenciais foram desafiados a reinventar esses encontros formativos que ocorriam no polo $U A B$, criando estratégias de interação mediadas pelas tecnologias digitais. Nesse sentido, o objetivo deste artigo é apresentar um relato de experiência sobre duas estratégias pedagógicas planejadas pelos tutores presenciais dos polos de Águas Lindas de Goiás-GO e Catalão-GO e desenvolvidas com os acadêmicos do curso de Pedagogia à distância do CEAR da UEG neste contexto de pandemia da COVID-19, com intuito de contribuir para a formação docente na perspectiva da educação das relações étnico-raciais e da pedagogia decolonial.

O artigo está dividido em duas partes. A primeira parte faz uma reflexão sobre a decolonialidade e a educação para as relações étnico-raciais. Em seguida, apresenta os relatos de experiência sobre as estratégias desenvolvidas para substituição do encontro presencial da disciplina História da Cultura Afro-brasileira e Indígena, destacando a participação dos 
acadêmicos e o alcance que as mesmas tomaram, formando uma comunidade de aprendizagem e trabalho em rede.

Antes de iniciar a primeira parte, destacamos que nossa prática enquanto trabalhadores da educação atuantes na Educação a Distância é embasada no conceito de Comunidade de Trabalho e Aprendizagem em Rede (CTAR) que tem como princípio e diretriz a afirmação de que uma "outra Educação a Distância é possível" (PONTES; CTAR, 2010). Nessa concepção, uma CTAR apoia-se nas seguintes premissas:

1 - a convicção em que uma educação tecnológica pode ser baseada no diálogo, em oposição à mera transmissão verticalizada e assimétrica de conteúdos e conhecimentos; 2 - a ação cooperativa e colaborativa entre os sujeitos deve prevalecer sobre a competição individualizada; 3 - a aprendizagem deve valorizar o trabalho reflexivo, em vez do simples acúmulo de informações; 4 - a comunicação em rede deve voltar-se para a convivência, em vez de levar ao isolamento no individualismo; 5 - e, finalmente, a afirmação de uma educação a distância direcionada para uma ação transformadora, em vez de atividade meramente reprodutora de conhecimentos sem compromisso com a mudança da realidade dos educandos (PONTES; CTAR, 2010, p. 22).

Além do mais, como tutores presenciais, compomos uma equipe multidisciplinar responsável por materializar as diretrizes da política nacional de Educação a Distância e de formação de profissionais da educação. Conforme Souza et al. (2017, p. 418), "a tutoria presencial é a mola mestra do processo de ensino e aprendizagem na modalidade a distância, uma vez que sua principal função consiste na mediação, ou seja, aproximar a universidade dos alunos e motivar sua permanência no curso".

Atuando diretamente nos polos de apoio da UAB, os tutores presenciais fazem a mediação e orientação presencial dos acadêmicos no desenvolvimento das atividades do curso, sejam virtuais ou não. Nos dias de encontro presencial, são os tutores presenciais que organizam as atividades, aplicam as avaliações, corrigem e lançam as notas no ambiente virtual de aprendizagem. Faz parte, também, das atribuições dos tutores presenciais, solucionar dúvidas dos acadêmicos tanto com relação ao uso do ambiente virtual de aprendizagem quanto com relação às atividades virtuais de modo mais individual a fim de auxiliar na superação de dificuldades técnicas, pedagógicas, gerenciais e outras.

Enquanto formadores de profissionais da educação, compreendemos que temos a função de formar cidadãos críticos capazes de se posicionar na realidade social perante as desigualdades e preconceitos sociais. O preconceito étnico-racial é ainda muito forte na cultura brasileira, e, por conseguinte, na escola, o que demanda uma intervenção contínua por parte dos profissionais da educação no sentido de levarem os alunos a desconstruírem preconceitos e criarem um clima de convivência escolar com relações pautadas no respeito às diferenças.

Assim, as duas estratégias pedagógicas que desenvolvemos junto aos acadêmicos tiveram o intuito de favorecer o reconhecimento da diversidade cultural e pluralidade étnico-racial existente na sociedade brasileira, para que sejam capazes de atuar enquanto agentes transformadores e promotores da igualdade étnico-racial. Além disso, julgamos fundamental introduzir as reflexões decoloniais na formação desses futuros profissionais da educação para que tenham capacidade de superar a colonialidade do poder, do saber e do ser e formar pessoas 
mais conscientes da história do Brasil e da sua própria identidade, enquanto sujeitos históricos, sociais e culturais.

\section{DECOLONIALIDADE E EDUCAÇÃO PARA AS RELAÇÕES ÉTNICO-RACIAIS}

No Brasil e no exterior, em círculos acadêmicos de diversas áreas, as discussões sobre a decolonialidade estão em voga. Essas discussões estão associadas à linha teórica latinoamericana denominada Decolonialidade, ou Estudos Decoloniais, que tem por objetivo questionar saberes eurocentrados sobre os vários povos da América Latina construídos enquanto subalternos e ao mesmo tempo construir novas narrativas, cosmologias e saberes contrahegemônicos que se oponham a preconceitos e epistemologias dominantes construídos pelos povos europeus.

Para compreender a formação da corrente teórica da decolonialidade, é preciso resgatar alguns elementos históricos. De acordo com Ballestrin (2013), no ano de 1992, a partir da reimpressão do texto Colonialidad y modernidad/racionalidad de Aníbal Quijano, um grupo de intelectuais latino-americanos que viviam nos Estados Unidos fundaram o Grupo LatinoAmericano de Estudos Subalternos, inspirado no Grupo Sul-Asiático dos Estudos Subalternos. A ideia era estudar o subalterno na América Latina, que fora esquecido pelos estudos pós-coloniais e subalternos que não conseguiram romper com visões eurocêntricas.

Entretanto, de acordo com Ballestrin (2013), em razão de divergências teóricas, o Grupo Latino-Americano de Estudos Subalternos foi desagregado em 1998. Alguns membros realizaram outros encontros e posteriormente fundaram o Grupo Modernidade/Colonialidade, que foi criado no final dos anos de 1990 por intelectuais latino-americanos pertencentes a várias universidades das Américas. Esse grupo produziu inúmeras contribuições analíticas, tais como:

a) a narrativa original que resgata e insere a América Latina como o continente fundacional do colonialismo, e, portanto, da modernidade; (b) a importância da América Latina como primeiro laboratório de teste para o racismo a serviço do colonialismo; (c) o reconhecimento da diferença colonial, uma diferença mais difícil de identificação empírica na atualidade, mas que fundamenta algumas origens de outras diferenças; (d) a verificação da estrutura opressora do tripé colonialidade do poder, saber e ser como forma de denunciar e atualizar a continuidade da colonização e do imperialismo, mesmo findados os marcos históricos de ambos os processos; (e) a perspectiva decolonial, que fornece novos horizontes utópicos e radicais para o pensamento da libertação humana, em diálogo com a produção de conhecimento (BALLESTRIN, 2013, p. 110).

Postas essas considerações iniciais, é importante diferenciar colonialismo e colonialidade. Colonialismo é a dominação político-econômica de alguns povos sobre outros e existe há milhares de anos antes da colonialidade (QUIJANO, 2002). O colonialismo pode ser entendido como as situações coloniais impostas pela presença de administrações coloniais (GROSFOGUEL, 2009), como ocorreu no Brasil colônia. 
A colonialidade equivale a uma matriz colonial de poder oculta atrás da retórica da modernidade. Essa matriz opera sobre vários "nós histórico-estruturais heterogêneos" interrelacionados e é construída pela episteme eurocêntrica que fundou hierarquias múltiplas e uma concepção universal de sujeito (MIGNOLO, 2017). O conceito de colonialidade evidencia que mesmo com o fim do colonialismo, a lógica da colonialidade não acabou e continua sendo reproduzida e operando de diferentes maneiras, produzindo hierarquias e injustiças sociais.

Nesse contexto, é importante destacar o conceito de colonialidade do poder desenvolvido por Aníbal Quijano no ano de 1989 (BALLESTRIN, 2013). Para Quijano (2005), a colonialidade é um dos elementos constitutivos do padrão mundial do poder capitalista, que estabeleceu a classificação da população em termos raciais e étnicos, com o objetivo de explorar a mão de obra de povos indígenas e negros, permitindo que a Europa se constituísse como o centro do mundo capitalista.

A conquista da América em 1492 é o marco da constituição da modernidade, que tem a colonialidade como o seu lado obscuro e necessário (MIGNOLO, 2017). Essa data também marca a constituição de um novo padrão de poder mundial que, para Quijano (2002), consiste na articulação de quatro domínios: a colonialidade do poder, o capitalismo, o Estado e o eurocentrismo.

1) a colonialidade do poder, isto é, a ideia de "raça" como fundamento do padrão universal de classificação social básica e de dominação social; 2) o capitalismo, como padrão universal de exploração social; 3) o Estado como forma central universal de controle da autoridade coletiva e o moderno Estadonação como sua variante hegemônica; 4) o eurocentrismo como forma hegemônica de controle da subjetividade/intersubjetividade, em particular no modo de produzir conhecimento (QUIJANO, 2002, p. 4).

Conforme Ballestrin (2013), o conceito de colonialidade do poder, posteriormente, foi estendido para outros âmbitos que não apenas o poder. Grosfoguel (2009), por exemplo, compreende a colonialidade do poder como um enredamento ou uma interseccionalidade de múltiplas e heterogêneas hierarquias globais, "heterarquias", de formas de dominação e exploração sexual, política, epistémica, económica, espiritual, linguística e racial.

Nesse sentido, a partir da perspectiva decolonial, pode-se dizer que a formação da sociedade brasileira está inserida numa longa história de dominação eurocêntrica, capitalista, imperialista e de colonização das Américas, que produziu e reforçou desigualdades, bem como hierarquias de classe, étnico-raciais, de gênero, sexuais, espirituais, econômicas, políticas, linguísticas, geográficas e epistêmicas (QUIJANO, 2002; GROSFOGUEL, 2009; MIGNOLO, 2017).

Ballestrin (2013) enfatiza que a colonialidade se reproduz por meio de uma tripla dimensão: do poder, do saber e do ser. Essas noções foram elaboradas de várias formas pelo Grupo Modernidade/Colonialidade. A colonialidade do poder localiza-se numa esfera políticoeconômica. A colonialidade do saber está numa esfera epistêmica e epistemológica, enquanto a colonialidade do ser, numa esfera ontológica.

A colonialidade do saber está ligada ao eurocentrismo que, além de desvalorizar os saberes não europeus, impõe uma visão de mundo eurocentrada, buscando exercer a dominação por meio do conhecimento. A colonialidade do ser, conceito desenvolvido por Maldonado-Torres 
(2007), evidencia os efeitos da colonialidade sobre a experiência vivida e a subjetividade de sujeitos subalternos.

Tomar consciência do processo histórico de construção das desigualdades e dos efeitos da colonialidade do poder, do saber e do ser é uma tarefa fundamental para qualquer profissional da educação. É necessário compreender que a colonialidade promove o controle, a exploração em vários domínios, tais como do trabalho, da autoridade, da natureza, do gênero, da sexualidade, da subjetividade e do conhecimento (QUIJANO, 2005; BALLESTRIN, 2013).

Cientes da necessidade de superar a colonialidade do poder, do ser e do saber (QUIJANO, 2002; MALDONADO-TORRES, 2007; BALLESTRIN, 2013) e de construir práticas pedagógicas que reconheçam a contribuição de povos e grupos sociais que costumeiramente tem suas culturas, conhecimentos, identidades e experiências desvalorizados, negados e colocados à margem dos currículos escolares, como os negros e indígenas, buscamos - enquanto professor e professora que somos - desenvolver em nossas práticas uma "outra pedagogia". Dessa forma, dialogamos com a proposta de Walsh (2009) de construção de uma pedagogia decolonial. Uma ação decolonial enquanto pedagogia requer

[...] um trabalho que procura desafiar e derrubar as estruturas sociais, políticas e epistêmicas da colonialidade - estruturas até agora permanentes - que mantêm padrões de poder enraizados na racialização, no conhecimento eurocêntrico e na inferiorização de alguns seres como menos humanos (WALSH, 2009, p. 24).

Desenvolver uma pedagogia decolonial requer que profissionais da educação construam uma visão crítica sobre a história do Brasil e sejam capazes de atuar na formação de crianças, adolescentes, jovens e adultos enquanto agentes questionadores de saberes que cultivam preconceitos étnico-raciais. Estudar a decolonialidade permite que profissionais da educação construam uma consciência histórica sobre processos de construção social das desigualdades e das diferenças. Além disso, é possível construir uma visão sobre sua própria história enquanto sujeito histórico, social e cultural.

Na educação brasileira, o artigo 26-A da Lei de Diretrizes e Bases da Educação Nacional, Lei n 9.394/1996, estabeleceu que é obrigatório o ensino da História e Cultura Afro-Brasileira e Indígena nas escolas de ensino fundamental e médio (BRASIL, 1996). Conforme a Resolução n 1 , de 17 de junho de 2004, que instituiu as Diretrizes Curriculares Nacionais (DCN) para a Educação das Relações Étnico-Raciais e para o Ensino de História e Cultura Afro-Brasileira e Africana,

[...] a Educação das Relações Étnico-Raciais tem por objetivo a divulgação e produção de conhecimentos, bem como de atitudes, posturas e valores que eduquem cidadãos quanto à pluralidade étnico-racial, tornando-os capazes de interagir e de negociar objetivos comuns que garantam, a todos, respeito aos direitos legais e valorização de identidade, na busca da consolidação da democracia brasileira (BRASIL, 2004, p. 11).

Sendo assim, a disciplina História da Cultura Afro-brasileira e Indígena, ofertada pelo Curso de Licenciatura em Pedagogia à distância do CEAR/UEG, buscou contribuir na formação de pedagogos para que sejam capazes de implementar o artigo 26-A da Lei n 9.394/1996, a partir 
das DCN para a Educação das Relações Étnico-Raciais e para o Ensino de História e Cultura AfroBrasileira e Africana.

A disciplina abordou diversos conteúdos sobre a diversidade étnico-racial, discutindo as políticas e legislações educacionais antirracistas, o racismo, as religiões de matriz africana e indígena, a diáspora africana e a resistência indígena e quilombola, entre outros. Apesar disso, não trouxe nenhum conteúdo que abordasse as reflexões decoloniais. Esse foi um dos motivos que levou as tutorias presenciais dos polos de Águas Lindas de Goiás-GO e Catalão-GO a desenvolver estratégias que rompessem com esse silenciamento curricular.

\section{ESTRATÉGIAS PEDAGÓGICAS PARA UMA FORMAÇÃO DECOLONIAL}

\subsection{Aprendizagem baseada em problemas}

A Aprendizagem Baseada em Problemas (ABP) é uma metodologia ativa de aprendizagem que compreende o estudante como o centro do processo de ensino e aprendizagem, incentivando o estudo e a pesquisa a partir da resolução de problemas da realidade (BERBEL, 1998).

A metodologia da ABP prevê a formação de grupos tutoriais de estudantes que devem interagir entre si para resolver uma situação problema. O grupo tutorial deve seguir alguns passos ou etapas que, na literatura sobre a ABP, costumam variar, mas basicamente correspondem:

1. Leitura do problema, identificação e esclarecimento de termos desconhecidos; 2. Identificação dos problemas propostos pelo enunciado; 3. Formulação de hipóteses explicativas para os problemas identificados no passo anterior (os alunos se utilizam nesta fase dos conhecimentos de que dispõem sobre o assunto); 4. Resumo das hipóteses; 5. Formulação dos objetivos de aprendizado (trata-se da identificação do que o aluno deverá estudar para aprofundar os conhecimentos incompletos formulados nas hipóteses explicativas); 6. Estudo individual dos assuntos levantados nos objetivos de aprendizado; 7. Retorno ao grupo tutorial para rediscussão do problema frente aos novos conhecimentos adquiridos na fase de estudo anterior (BERBEL, 1998, p. 147).

Trabalhar com a aprendizagem baseada em problemas não é uma tarefa simples. Além do conhecimento sobre como funciona a metodologia, é necessário que os estudantes assumam uma postura ativa perante seu processo de aprendizagem. Assim, a primeira orientação antes de apresentar a situação-problema aos estudantes do polo de Águas Lindas de Goiás-GO foi que pesquisassem acerca da ABP. O tutor presencial enviou dois vídeos sobre a metodologia para facilitar o entendimento de como a atividade seria desenvolvida. Em razão da pandemia da COVID-19, os grupos tutoriais foram formados por meio do recurso grupos do WhatsApp. O tutor presencial pediu para os acadêmicos organizarem-se e criarem grupos de cinco pessoas pelo WhatsApp. Foram formados seis grupos e escolhidos os coordenadores de cada um.

Após a formação dos grupos, no dia seguinte, foi apresentada a situação problema Quadro 1 - para cada grupo. A partir da leitura da situação problema, os acadêmicos deveriam 
encontrar os termos desconhecidos e pesquisar seus significados. Além disso, deveriam formular em grupo três perguntas que contemplassem os termos desconhecidos e a situação problema. Essas perguntas viraram os objetivos de aprendizagem do grupo. $O$ tutor presencial mediou, quando necessário, as interações nos grupos e tirou dúvidas. Após estudo e interação coletiva, foi realizada uma chamada de vídeo pelo WhatsApp com cada grupo para que socializassem o que haviam aprendido com a atividade e apresentassem a solução dada à situação problema. Todo o desenvolvimento dessa estratégia ocorreu entre os dias 1 a 9 de maio de 2020.

\section{Quadro 1: Situação-problema}

\section{Como descolonizar o saber, o poder, o ser e o viver na escola?}

Natália é uma professora dos anos iniciais do Ensino Fundamental numa escola da periferia. Nesse ano de 2020, a professora Natália está ministrando aulas para o 40 ano numa turma composta por crianças multirraciais. Todo ano ela trabalha conteúdos sobre a colonização do Brasil e os povos indígenas no Dia do Índio (19 de abril) e sobre a diáspora africana e escravidão no Dia da Consciência Negra (20 de novembro). Natália sempre se preocupa sobre o que fazer e o que não fazer ao abordar a cultura indígena e afrobrasileira em sala de aula. Um ponto que ela considera importante discutir com as crianças é se o Brasil foi descoberto ou conquistado. Ao fazer um curso de formação de docentes sobre educação para a igualdade étnico-racial, a professora Natália descobriu que abordar esses conteúdos somente em datas comemorativas pode configurar um currículo turístico. Este ano ela quer fazer diferente. Pretende criar um projeto educativo que aborde gradativamente temáticas étnico-raciais com culminância nas datas comemorativas. Ela descobriu um método/pensamento decolonial que tem como meta a reconstrução radical do saber, do poder, do ser e do viver. Embora tenha experiência em abordar conteúdos sobre cultura indígena e afro-brasileira em sala de aula, ela não possui os saberes docentes necessários para desenvolver o projeto baseado nesse método/pensamento. Mas ela está pesquisando e planejando atividades sobre a diáspora africana e a questão indígena baseada nesse método/pensamento. Nessas pesquisas ela se questionou: é possível descolonizar o saber, o poder, o ser e o viver na escola? Como fazer isso?

Fonte: elaborado pelo autor (2021).

Dos seis grupos criados, quatro interagiram colaborativamente usando o WhatsApp e exploraram suas funcionalidades, compartilhando as pesquisas realizadas e enviando áudios, vídeos, imagens e textos. Os outros dois grupos interagiram pouco e apresentaram dificuldades de entender a atividade, o que exigiu uma mediação maior do tutor presencial.

A maioria das impressões dos estudantes sobre a atividade foram positivas, sendo que para alguns foi a atividade mais interessante que fizeram durante o curso. Muitos estudantes destacaram que a pesquisa e o diálogo em grupo foram os aspectos mais significativos da atividade. Ainda, houve estudantes, poucos, que consideraram a atividade confusa e sem objetivos precisos, além de enfatizarem que a criação de um grupo no WhatsApp não era necessário. Nesse caso, percebemos que alguns estudantes demostraram resistências por nunca terem desenvolvido esse tipo de atividade e também por ser difícil abandonar práticas de ensino e aprendizagem tradicionais e assumir uma postura mais ativa perante sua aprendizagem.

A vivência mostrou que a ABP é uma estratégia potente para desenvolver a aprendizagem, porque engaja os acadêmicos a pesquisarem, conhecerem e elaborarem conceitos e resolver problemas da realidade, articulando teoria e prática.

Nessa atividade, os acadêmicos puderem conhecer e construir noções básicas sobre os conceitos de decolonialidade, epistemicídio, eurocêntrico, currículo turístico, genocídio, fenótipo, genótipo, diáspora africana, entre outros. Além disso, puderem refletir sobre como 
desenvolver práticas e pedagogias decoloniais que sejam capazes de questionar visões universalizantes e etnocêntricas sobre os povos indígenas e negros.

Em suma, os acadêmicos entenderam a necessidade de desconstruir visões eurocêntricas ao trabalhar conteúdos sobre a história do Brasil e sobre os povos indígenas e negros. Da mesma forma, perceberam que as práticas educativas ainda estão impregnadas de preconceitos étnicoraciais. Muitos acadêmicos, por exemplo, ressaltaram que não tinham noção da diversidade dos povos indígenas, nem dos povos do continente africano. Esse fato acabava alimentando uma "história única" a respeito desses povos.

O mais interessante foi notar que essa atividade ultrapassou os limites dos grupos de WhatsApp e da própria Universidade Estadual de Goiás, configurando uma verdadeira comunidade de aprendizagem e trabalho em rede. Um acadêmico levou as questões construídas pelo seu grupo para colegas especialistas de outras instituições, mestres e doutores com trajetória de pesquisa sobre educação das relações étnico-raciais. Esses especialistas responderam as questões com áudios e textos de sugestões, agregando mais conhecimentos e possibilitando potenciar a aprendizagem de toda a turma, tendo em vista que suas contribuições foram socializadas com os demais grupos.

Nesse sentido, a atividade favoreceu o desenvolvimento de uma aprendizagem dialógica (DOTTA, 2014), fomentando a colaboração e a problematização em grupo. De maneira inesperada, a atividade com o uso da aprendizagem baseada em problemas foi capaz de ir além dos muros da universidade, como foi também o caso da webconferência com especialista realizada no polo de Catalão-GO.

\subsection{Webconferência com especialista}

A webconferência é uma estratégia pedagógica que permite a comunicação síncrona, ou seja, em tempo real com várias pessoas que podem estar em diversos locais. Por meio da webconferência é possível usar várias ferramentas de comunicação - áudio, vídeo e texto, o que a torna multimodal -, assim como fazer o compartilhamento de arquivos, aplicativos, telas de computador, etc. - o que a torna multimídia. $\mathrm{O}$ uso da webconferência em cursos on-line pode aumentar a qualidade dos cursos e amplificar a aprendizagem (DOTTA, 2014).

Para introduzir as reflexões decoloniais na formação de futuros pedagogos, a estratégia escolhida pela tutora presencial do polo de Catalão-GO foi a webconferência multimodal e multimídia com especialista. A ferramenta escolhida para comunicação síncrona foi o Google Meet, que durante a pandemia da COVID-19 teve diversas funcionalidades liberadas de forma gratuita pelo Google. Foi convidado o professor Giovani José da Silva, que tem graduação, mestrado e doutorado em História, além de uma larga experiência de pesquisa e vivência com as temáticas e os povos indígenas, tendo vivido entre os povos indígenas da etnia Kadiwéu de 1997 a 2004, retomando os contatos a partir de 2016.

Inicialmente, a ideia da webconferência era realizar um debate sobre como ensinar a cultura indígena no ambiente escolar, sem reproduzir estereótipos e visões preconceituosas sobre os povos indígenas brasileiros. Ainda no planejamento da aula virtual síncrona, o tutor presencial do polo de Águas Lindas de Goiás-GO apresentou para a tutora presencial do polo de 
Catalão-GO a situação problema que criou e desenvolveu com acadêmicos do seu polo. Ao ler sua proposta, logo surgiu um novo tema: a pedagogia decolonial.

O professor Giovani aceitou o desafio de abordar esse tema. Inclusive, suas investigações são inspiradas nas reflexões decoloniais. Dessa forma, foram realizadas duas webconferências. A primeira aconteceu no dia 16 de maio de 2020 com o tema Café \& História - Como descolonizar o saber, o poder, o ser e o viver na escola? e a segunda ocorreu no dia 30 de maio de 2020 com o tema Café \& História 2 - Como descolonizar o saber, o poder, o ser e o viver na formação de professores?

A escolha pelo nome Café \& História tinha dois significados: Café se justifica porque o encontro foi marcado no sábado de manhã e a intenção era ser um momento descontraído como tomar café da manhã e saborear os "saberes da experiência" (BONDÍA, 2002) que seriam compartilhados pelo professor Giovani; História remete à disciplina "História da Cultura Afrobrasileira e Indígena”. O restante do título era inspiração das problematizações da decolonialidade, provocadas pela situação problema apresentada pelo tutor e parceiro de tutoria de Águas Lindas de Goiás-GO.

No desenvolvimento das webconferências, o professor Giovani promoveu várias reflexões sobre os saberes e a pedagogia decolonial. Para muitos acadêmicos, esses conhecimentos eram novidade. Todas as pessoas que participaram dessas atividades puderam aprender sobre a importância de trabalhar a temática indígena através da visão dos povos indígenas e não dos povos europeus. Foi possível também reconhecer a pluralidade dos próprios povos indígenas, evitando visões generalistas e simplificadas sobre as diversas etnias, bem como aprender sobre a necessidade de trabalhar as temáticas africanas e negras considerando a diversidade dos povos africanos e negros e partir das suas visões e não de um ponto de vista eurocentrado.

Ouvir as histórias do Giovani sobre suas vivências e aprendizagens junto aos povos da etnia Kadiwéu foi uma excelente experiência para todas as pessoas que estiveram presentes nessas duas webconferências. Como afirma Bondía (2002, p. 21), "a experiência é o que nos passa, o que nos acontece, o que nos toca". Sem dúvidas, esses momentos marcaram a formação dos acadêmicos do curso de Pedagogia, tocando suas identidades e subjetividades, provocando a construção de novos conhecimentos. Foram momentos que proporcionaram construir uma nova visão da história e que destacaram a importância de estarmos problematizando nossos próprios saberes, culturas e visões.

O que era para ser uma aula virtual restrita a acadêmicos do curso de Licenciatura em Pedagogia do polo de Catalão-GO e Águas Lindas de Goiás-GO tomou uma dimensão que não imaginávamos. Os acadêmicos do curso de Licenciatura em História da UEG do polo de CatalãoGO também foram convidados; mas, para além desses, as duas webconferências agregaram um público de pessoas de outras universidades e espaços formativos interessadas no assunto. Dessa forma, foi formada uma Comunidade de Trabalho e Aprendizagem em Rede (CTAR), ou seja, uma "educação aberta, apoiada na pedagogia da autonomia, exercida numa comunidade de trabalho e aprendizagem em rede, utilizando com propriedade as tecnologias de informação e de comunicação" (PONTES; CTAR, 2010, p. 22).

A atividade teve participação de estudantes da Universidade Federal do Amapá (UNIFAP), do Programa de Mestrado Profissional em Ensino de História (ProfHistória) da Universidade do 
Estado da Bahia (UNEB) e de outros lugares que nem foi possível identificar, tendo em vista a divulgação feita pelo professor Giovani em suas redes sociais e nos locais em que atua como docente. O Google Meet contabilizou a participação de 72 pessoas nas duas webconferências realizadas, que tiveram a média de duas horas cada.

As webconferências foram momentos de reflexões e problematizações sobre o nosso ser, saber e viver. Nesses momentos, os acadêmicos repensaram sobre as palavras racistas presente em nossa linguagem, os preconceitos que construímos, as formas como agimos, as leituras que fazemos, o que consumimos, entre outras coisas. Giovani problematizou sobre o que aprendemos e nos presenteou com conhecimentos que, para muitos acadêmicos, eram novidade.

Nesse percurso, aprendemos que não podemos "dar voz" a ninguém, porque as pessoas já possuem sua própria voz. O que podemos dar a elas são nossos ouvidos. Aprendemos, também, a tomar cuidado com as palavras porque elas podem ser bem ditas ou "malditas". Afinal, o preconceito étnico-racial muitas vezes é expresso por meio da linguagem e do pensamento eurocêntrico. Portanto, desconstruir esse preconceito é também desconstruir linguagens e conhecimentos que são aprendidos na socialização.

Ainda, foi possível conhecer um pouco das ideias de Catherine Walsh, Linda Tuhiwai Smith, Silvia Rivera Cusicanqui, Frantz Fanon e Paulo Freire. Todos os acadêmicos presentes nas webconferências puderam fazer perguntas e tirar dúvidas com o professor Giovani, além de usarem o chat para registrar seus comentários. Consequentemente, a atividade não se configurou como um webinário em que só uma pessoa fala e as demais escutam. 0 diálogo entre todas as pessoas presentes foi valorizado, potencializando os processos de aprendizagem e as trocas de conhecimento.

Os acadêmicos avaliaram de forma positiva as duas webconferências e afirmaram ter construído novos saberes com essas experiências. A sensação ao final dessas webconferências foi de dever cumprido e de ter colaborado para formar futuros pedagogos, professores de História e demais pessoas presentes para desenvolver uma prática pedagógica que questione preconceitos contra povos indígenas e negros, sendo capazes de promover uma educação para as relações étnico-raciais.

\section{CONSIDERAÇÕES FINAIS}

É inegável que a pandemia da COVID-19 impactou em várias áreas, sobretudo, na educação. A pandemia exigiu que os diversos profissionais da educação buscassem alternativas e estratégias pedagógicas que pudessem minimizar os seus impactos, sendo o Ensino Remoto Emergencial uma das principais alternativas adotadas.

No curso de Pedagogia à distância da Universidade Estadual de Goiás, a educação mediada por tecnologias digitais já era uma realidade antes da pandemia da COVID-19. Assim, os acadêmicos já estavam familiarizados com o uso dessas tecnologias. A grande novidade foi transformar os encontros presenciais em encontros virtuais, mantendo o diálogo entre estudantes-estudantes e estudantes-tutores presenciais. 
Em meio a esse contexto, também era necessário continuar desenvolvendo o exercício de tutoria presencial de forma crítica e com qualidade. Por conta dos saberes construídos em nossas trajetórias profissional, de vida e em embasamentos teóricos, políticos e pedagógicos explicitados nesse relato de experiência, o exercício da tutoria presencial da disciplina História da Cultura Afro-brasileira e Indígena não ocorreu de forma vaga. Sentimos que era preciso ir além do currículo prescrito e contornar a ausência da decolonialidade na formação docente mediante o planejamento e desenvolvimento de estratégias pedagógicas que introduzissem os saberes decoloniais na formação de acadêmicos de Pedagogia e História da Universidade Estadual de Goiás dos polos de Águas Lindas de Goiás-GO e Catalão-GO.

Além de criar espaços formativos para os acadêmicos, enquanto tutores presenciais, também nos formamos nessas experiências e percebemos que para construir currículos decoloniais na formação docente é preciso primeiro nos descolonizar. Assim, tivemos a oportunidade de refletir sobre a nossa prática pedagógica e passamos a tentar fazer ainda mais o exercício de nos libertar de práticas tradicionais de educação bancária que estão mais interessadas em cobrar respostas dos estudantes em detrimento de incentivá-los a fazer perguntas, duvidar e pesquisar.

A Aprendizagem Baseada em Problemas e a Webconferência com especialista foram estratégias que visaram cooperar para a formação docente numa perspectiva decolonial. Temos consciência de que as estratégias desenvolvidas não são suficientes para transformar um profundo e histórico processo de colonização do ser, do saber, do poder e do viver, mas acreditamos que podem ter sido o início de um processo de "desaprendizagem" de preconceitos e de aprendizagem de novos conhecimentos por parte dos acadêmicos que participaram. Mesmo que pontualmente, contribuímos para suscitar e abrir questionamentos, bem como novos horizontes de pesquisa para os acadêmicos, convocando-os a tomar uma postura decolonial perante a vida e as suas futuras práticas docentes.

\section{REFERÊNCIAS}

BALLESTRIN, L. América Latina e o giro decolonial. Revista Brasileira de Ciência Política, Brasília, n. 11, p. 89-117, 2013. Disponível em:

https://www.scielo.br/j/rbcpol/a/DxkN3kQ3XdYYPbwwXH55jhv/abstract/?lang=pt. Acesso em: 16 jun. 2021.

BERBEL, N. A. N. A problematização e a aprendizagem baseada em problemas: diferentes termos ou diferentes caminhos?. Interface, Botucatu, v. 2, n. 2, p. 139-154, 1998. Disponível em:

https://www.scielo.br/j/icse/a/BBqnRMcdxXyvNSY3YfztH9J/?lang=pt. Acesso em: 16 jun. 2021.

BONDÍA, J. L. Notas sobre a experiência e o saber de experiência. Revista Brasileira de Educação, Rio de Janeiro, n. 19, p. 20-28, 2002. Disponível em:

https://www.scielo.br/j/rbedu/a/Ycc5QDzZKcYVspCNspZVDxC/?lang=pt\&format=pdf. Acesso em: 16 jun. 2021.

BRASIL. Conselho Nacional de Educação. Resolução n 1, de 17 de junho de 2004. Institui Diretrizes Curriculares Nacionais para a Educação das Relações Étnico-Raciais e para o Ensino de História e Cultura 
Afro-Brasileira e Africana. Diário Oficial da União: seção 1, Brasília, DF, ano 141, n. 118, p. 11, 22 jun. 2004. Disponível em: http://portal.mec.gov.br/cne/arquivos/pdf/res012004.pdf. Acesso em: 07 abr. 2020.

BRASIL. Lei n 9.394, de 20 de dezembro de 1996. Lei das Diretrizes e Bases da Educação Nacional. Estabelece as diretrizes e bases da educação nacional. Diário Oficial da União: seção 1, Brasília, DF, p. 27933, 23 dez. 1996. Disponível em: http://www.planalto.gov.br/ccivil_03/LEIS/I9394.htm. Acesso em: 07 abr. 2020.

BRASIL. Medida provisória $n^{\circ} 934$ de $1^{\circ}$ de abril de 2020. Estabelece normas excepcionais sobre o ano letivo da educação básica e do ensino superior decorrentes das medidas para enfrentamento da situação de emergência de saúde pública. Diário Oficial da União: seção 1: Extra, Brasília, DF, ano 158, n. 63-A, p. 1, 1 abr. 2020a. Disponível em: http://www.in.gov.br/en/web/dou/-/medida-provisoria-n-934-de-1-deabril-de-2020-250710591. Acesso em: 17 jul. 2020.

BRASIL. Ministério da Educação. Portaria $n^{\circ} 343$, de 17 de março de 2020. Dispõe sobre a substituição das aulas presenciais por aulas em meios digitais enquanto durar a situação de pandemia do novo Coronavírus - COVID-19. Diário Oficial da União: seção 1, Brasília, DF, ano 158, n. 53, p. 39, 18 mar. 2020b. Disponível em: https://www.in.gov.br/en/web/dou/-/portaria-n-343-de-17-de-marco-de-2020-248564376. Acesso em: 11 dez. 2020.

BRASIL. Ministério da Educação. Portaria $n^{\circ} 345$, de 19 de março de 2020. Altera a Portaria MEC $n^{\circ} 343$, de 17 de março de 2020. Diário Oficial da União: seção 1 - Extra, Brasília, DF, ano 158, n. 54-D, p. 1, 19 mar. 2020c. Disponível em: https://www.in.gov.br/web/dou/-/portaria-n-345-de-19-de-marco-de-2020248881422. Acesso em: 11 dez. 2020.

BRASIL. Ministério da Educação. Portaria $n^{\circ} 473$, de 12 de maio de 2020. Prorroga o prazo previsto no $\S 1^{\circ}$ do art. $1^{\circ}$ da Portaria $n^{\circ} 343$, de 17 de março de 2020. Diário Oficial da União: seção 1, Brasília, DF, ano 158, n. 90, p. 55, 13 maio 2020d. Disponível em: https://www.in.gov.br/en/web/dou/-/portaria-n-473-de12-de-maio-de-2020-

256531507? inheritRedirect=true\&redirect=\%2Fweb\%2Fguest\%2Fsearch\%3FqSearch\%3DPortaria\%25204 73\%252C\%252012\%2520de\%2520maio\%2520de\%25202020. Acesso em: 11 dez. 2020.

BRASIL. Ministério da Educação. Portaria n 544, de 16 de Junho de 2020. Dispõe sobre a substituição das aulas presenciais por aulas em meios digitais, enquanto durar a situação de pandemia do novo coronavírus - Covid-19, e revoga as Portarias MEC $n^{\circ} 343$, de 17 de março de 2020, $n^{\circ} 345$, de 19 de março de 2020, e n ${ }^{\circ}$ 473, de 12 de maio de 2020. Diário Oficial da União: sessão 1, Brasília, DF, ano 158, n. 114, p. 62, 17 jun. 2020e. Disponível em: http://www.in.gov.br/en/web/dou/-/portaria-n-544-de-16-de-junho-de2020-261924872. Acesso em: 10 jun. 2021.

DOTTA, S. Webconferência multimodal e multimídia. In: DOTTA, S. (org.). Aulas virtuais síncronas: condução de webconferência multimodal e multimídia em Educação a Distância. São Paulo: Editora UFABC, 2014.

GOIÁS. Decreto $n^{\circ}$ 9.633, de 13 de março de 2020. Dispõe sobre a decretação de situação de emergência na saúde pública do Estado de Goiás, em razão da disseminação do novo coronavírus (2019-nCoV). Diário Oficial do Estado de Goiás: suplemento: Poder Executivo, Goiânia, ano 183, n. 23.257, p. 1, 13 mar. 2020a. Disponível em: https://legisla.casacivil.go.gov.br/pesquisa_legislacao/103012/decreto-9633. Acesso em: 17 jul. 2020.

GOIÁS. Secretaria-Geral da Governadoria. Conselho Estadual de Educação de Goiás. Resolução nº 02/2020, de 17 de março de 2020. Dispõe sobre o regime especial de aulas não presenciais no Sistema Educativo do Estado de Goiás, como medida preventiva à disseminação do COVID-19. Goiânia: Conselho Estadual de Educação de Goiás, 2020b. Disponível em: https://cee.go.gov.br/resolucao-022020-sobre-oregime-especial-de-aulas-nao-presenciais/. Acesso em: 1 mai. 2021. 
GROSFOGUEL, R. Para descolonizar os estudos de economia política e os estudos pós-coloniais: transmodernidade, pensamento de fronteira e colonialidade global. Revista Periferia, Rio de Janeiro, $v$. 1, n. 2, jul./dez. 2009. Disponível em: https://www.e-

publicacoes.uerj.br/index.php/periferia/article/view/3428/0. Acesso em: 1 mai. 2021.

HODGES, C. et al. The difference between emergency remote teaching and online learning. EDUCAUSE Review, v. 27, p. 1-15, 2020. Disponível em: https://er.educause.edu/articles/2020/3/the-differencebetween-emergency-remote-teaching-and-online-learning. Acesso em: 5 jul. 2020.

MALDONADO-TORRES, N. Sobre la colonialidad del ser: contribuciones al desarrollo de un concepto. In: CASTRO-GÓMEZ, S.; GROSFOGUEL, R. (org.). El giro decolonial: reflexiones para una diversidad epistémica más allá del capitalismo global. Bogotá: Siglo del Hombre Editores, 2007.

MIGNOLO, W. Colonialidade: o lado mais escuro da modernidade. Revista Brasileira de Ciências Sociais, São Paulo, v. 32, n. 94, 2017. Disponível em:

https://www.scielo.br/j/rbcsoc/a/nKwQNPrx5Zr3yrMjh7tCZVk/abstract/?lang=pt. Acesso em: 1 mai. 2021.

PONTES, E. B.; CTAR, G. A Comunidade de Trabalho e Aprendizagem em Rede (CTAR) na Faculdade de Educação da UnB. In: SOUZA, A. M.; FIORENTINI, L. M. R.; RODRIGUES, M. A. M. (org.). Educação superior a distância: Comunidade de Trabalho e Aprendizagem em Rede (CTAR). Brasília: Universidade de Brasília, Faculdade de Educação, Editora da Universidade de Brasília, 2010.

QUIJANO, A. Colonialidade do poder, eurocentrismo e América Latina. In: LANDER, E. (org.). A colonialidade do saber: eurocentrismo e ciências sociais: Perspectivas latino-americanas. Ciudad Autónoma de Buenos Aires, Argentina: CLACSO, 2005.

QUIJANO, A. Colonialidade, poder, globalização e democracia. Revista Novos Rumos, São Paulo, ano 17, n. 37, p. 4-28, 2002. Disponível em:

https://revistas.marilia.unesp.br/index.php/novosrumos/article/view/2192. Acesso em: 1 mai. 2021.

SOUZA, S. A. et al. Tutoria presencial em polo UAB: relato de experiência no curso de Filosofia da UFSJ Universidade Federal de São João Del-Rei. EmRede: Revista de Educação a Distância, Porto Alegre, v. 4, n. 2, p. 418-432, 2017. Disponível em:

https://www.aunirede.org.br/revista/index.php/emrede/article/view/229. Acesso em: 1 mai. 2021.

UNIVERSIDADE ESTADUAL DE GOIÁS (UEG). Reitoria. Instrução Normativa n. 80/2020. Estabelece o Plano Emergencial de Ensino e Aprendizagem (PEEA) para os cursos de graduação da UEG. Anápolis: Universidade Estadual de Goiás, 25 mar. 2020c. Disponível em: https://site.educacao.go.gov.br/wpcontent/uploads/2020/04/Instru\%C3\%A7\%C3\%A30-Normativa-n\%C2\%BA-80-2020-UEG.pdf. Acesso em: 1 mai. 2021.

UNIVERSIDADE ESTADUAL DE GOIÁS (UEG). Reitoria. Portaria n. 560/2020 - UEG. Estabelece medidas a serem adotadas, no âmbito da Universidade Estadual de Goiás, a fim de prevenir contaminação pelo novo Coronavírus (Covid-19). Anápolis: Universidade Estadual de Goiás, 16 mar. 2020a. Disponível em: http://cdn.ueg.edu.br/source/universidade_estadual_de_goias_306/noticias/52386/Portaria_560_2020_ medidas_internas_a_fim_de_prevenir_contaminacao_pelo_novo_Coronavirus.pdf. Acesso em: 1 mai. 2021.

UNIVERSIDADE ESTADUAL DE GOIÁS (UEG). Reitoria. Portaria n. 563/2020 - UEG. Dispõe sobre o regime de revezamento e o sistema de teletrabalho, a serem implantados na Universidade Estadual de Goiás, como forma de prevenção da disseminação do novo Coronavírus (Covid-19). Anápolis: Universidade Estadual de Goiás, 16 mar. 2020b. Disponível em: http://cdn.ueg.edu.br/source/universidade_estadual_de_goias_306/noticias/52386/Portaria_563_2020_ 
implanta_na_UEG_sistema_de_teletrabalho_e_regime_de_revezamento_e_anexo.pdf. Acesso em: 1 mai. 2021.

WALSH, C. Interculturalidade Crítica e Pedagogia Decolonial: in-surgir, re-existir e re-viver. In: CANDAU, V. M. (org.). Educação intercultural na América Latina: entre concepções, tensões e propostas. Rio de Janeiro: 7 letras, 2009. 